Vegueta. Anuario de la Facultad de Geografía e Historia

21 (1), 2021, 153-182

eISSN: 2341-1112

https://doi.org/10.51349/veg.2021.1.07

\title{
La Ciudad Jardín de Las Palmas de Gran Canaria como paisaje cultural urbano
}

\section{The Ciudad Jardin Neighbourhood of Las Palmas de Gran Canaria as an Urban Cultural Landscape}

\author{
Guillermo Morales Matos \\ Universidad Carlos III de Madrid \\ http:/ / orcid.org/0000-0003-4977-4552 \\ gmorales@hum.uc3m.es \\ Santiago Hernández Torres* \\ Ayuntamiento de Las Palmas de Gran Canaria \\ Servicio de Urbanismo \\ http:/ / orcid.org/0000-0003-3513-6269 \\ shernand@laspalmasgc.es \\ María Yazmina Lozano Mas \\ Universidad Internacional del Atlántico Medio \\ http://orcid.org/0000-0002-1599-1930 \\ ylozanoest75@gmail.com
}

Recibido: 22/06/2020; Revisado: 28/09/2020; Aceptado: 22/10/2020

\begin{abstract}
Resumen
Los paisajes culturales de la ciudad requieren un constante análisis de su caracterización y dinamismo, entre otros aspectos de la participación e impronta sobre los valores y los retos que presentan en el desarrollo sostenible e integrado. A través del ejemplo de Ciudad Jardín (Las Palmas de Gran Canaria) se pretende una identificación de la estructura que los conforma, un balance de su proceso cronológico y subrayar varios retos en su conservación e integración urbana. Se aporta una estructura de referencia para identificar su presencia en la ciudad. Se resalta la complejidad en la comprensión de sus cualidades, requiriendo de técnicas de didáctica ciudadana y de puesta en valor del patrimonio que atesoran.
\end{abstract}

Palabras clave: Barrios históricos, paisajes urbanos, patrimonio cultural, análisis geográfico, didácticas.

*Autor de correspondencia / Corresponding author.

Copyright: (C) 2021 ULPGC. Este es un artículo de acceso abierto distribuido bajo los términos de la licencia Creative Commons Atribución-NoComercial-SinDerivar (by-nc-nd) Spain 3.0. 


\begin{abstract}
Among other aspects of their impact upon the values and challenges associated with sustainable, integrated development, the cultural landscapes of a city require continuous analysis of their characteristics and dynamics. Taking as an example Ciudad Jardín (Las Palmas de Gran Canaria), this article identifies the structure of such spaces, assesses its chronological processes, and highlights some challenges regarding its conservation and urban integration. The article provides a reference structure for identifying the presence of a cultural landscape within the city, and emphasizes the difficulties in understanding its characteristics, as this requires different techniques of civic education, as well as the appreciation of value in the heritage they possess.
\end{abstract}

Key words: Historic neighborhood, urban landscapes, cultural heritage, geographic analysis, didactics

\title{
1. INTRODUCCIÓN
}

Los paisajes culturales urbanos engloban espacios con una singularidad formal, histórica, social, arquitectónica o de funcionalidad, que testimonian las pautas específicas de apropiación de la ciudad europea y española por parte de la sociedad que la habita. Las urbes en el Archipiélago Canario no son una excepción. Esas cualidades han demostrado en las Islas recursos para la diferenciación de estos ámbitos en términos de potencial turístico o de competitividad residencial o de un dinamismo económico con valor añadido. Pero, también han advertido nichos de vulnerabilidad a través de su capacidad de acogida para ciertos usos que se renuevan o se introducen en estos barrios, demostrándose en un conjunto nada despreciable de conflictos y una degradación general de los valores. Esa relación nos interesa analizarla desde una mirada en la que proponemos combinar las competencias de la Geografía y la Ordenación del Territorio, con las de las Ciencias Históricas como disciplinas preocupadas en la ciudad, sus rasgos, sus dinámicas y sus desequilibrios.

Por el conocimiento del ámbito y por su idoneidad como laboratorio para desentrañar el problema que nos ocupa, el barrio de Ciudad Jardín se localiza en Las Palmas de Gran Canaria (Canarias, España) y es una unidad urbana de algo más de $85,8 \mathrm{Ha}$. Se desarrolla sobre la plataforma costera de la denominada ciudad baja entre el centro histórico de Vegueta y Triana y el centro neurálgico, comercial y turístico del Puerto e Istmo de Guanarteme.

Es un espacio consolidado por la urbanización que en buena medida conserva muchos rasgos del escenario de la primera mitad del siglo xx, como testimonio de un período específico del desarrollo de la urbe. Su carácter ya histórico, con una centuria de antigüedad en varios de sus elementos territoriales, y la especificidad de unas pautas concretas de ocupación del espacio y unos estilos constructivos, nos permite proponer la hipótesis de estar ante un paisaje cultural. Ello no sólo se plantea en los aspectos conceptuales sino como ejemplo claramente demostrativo de las oportunidades, retos y condicionantes de la realidad actual en este tipo de formaciones dentro del panorama español e internacional.

Sin embargo, el desarrollo de sus cualidades ha coexistido con su propio dinamismo como enclave urbano, en la adaptación del uso edificado a los distintos tiempos e intereses o en las eficacias de la gestión pública del patrimonio cultural que suponen una seria amenaza y su tratamiento es uno de los retos más significativos en su conservación. La propia literatura científica y la documentación oficial ha hecho hincapié en su generalización como problema 
común en gran parte de los centros o formaciones históricas de la ciudad española e internacional, siendo de hecho un capítulo recurrente en la dialéctica de los distintos niveles administrativos. Esta demostración se manifiesta en unos resultados de investigación cuyo trabajo asociado pretendía conseguir unos objetivos específicos.

De una parte, se consideraba importante la delimitación conceptual a partir de una estructura de elementos territoriales que conforman un paisaje cultural urbano, a los efectos de garantizar una adecuada comprensión de la hipótesis. Es indudable que el apoyo de una revisión crítica y bibliográfica del tema era imprescindible. De otra, era obligatorio sintetizar el proceso de creación, construcción y desarrollo cronológico del barrio de Ciudad Jardín que hoy concebimos como paisaje, compendiando el comportamiento del ámbito durante las etapas significativas de esa evolución.

$Y$, por último, perseguíamos desentrañar las manifestaciones espaciales que conforman globalmente dicha modalidad de entorno, en tanto que representación del patrimonio cultural de Las Palmas de Gran Canaria y sus derivaciones como valor territorial.

Proponemos exponer los resultados de la investigación desarrollada a partir de una primera delimitación del paisaje cultural urbano, de la que deriva una metodología basada en varias fases que nos van dibujando la configuración del entorno. La exposición histórica es fundamental, dibujando el proceso de construcción y desarrollo del espacio hasta la situación actual en la que se destaca su valía. Con este recorrido cronológico, se justifica la diferenciación morfológica del ámbito, comúnmente un barrio, en el contexto de la ciudad. También, se identifican los valores que definen su condición de paisaje cultural, haciendo espacial énfasis en sus rasgos distintivos como entorno histórico en sus aspectos de configuración urbana, de compendio arquitectónico y su conjunto de pautas constructivas y artísticas, de cualidades ambientales, etc. Por último, se caracterizan los comportamientos contemporáneos como espacio urbano, observando las tensiones y muestras positivas de integración entre esos dinamismos y la valía paisajística.

\section{REVISIÓN CRÍTICA Y DELIMITACIÓN DEL PAISAJE URBANO CULTURAL}

La condición de Ciudad Jardín como paisaje urbano cultural se refiere a un concepto sobre el que se ha reflexionado desde diversas disciplinas durante al menos las dos últimas décadas. Geógrafos, historiadores, arquitectos, especialistas en Derecho, artistas y otras especialidades han hecho posible la disposición de una «biblioteca» de referencias que nos permite una revisión crítica y un estado de la cuestión que consideramos imprescindible en los objetivos de la investigación.

Como premisa de partida, está documentado que ya desde el Renacimiento se ha venido disertando sobre la condición de los monumentos urbanos como objetos de reflexión y contemplación, en alusión a la reconsideración de las ruinas de la Antigüedad Clásica tomando como base su condición histórica o su estimación como obras de arte de un valor universalmente aceptables (GonZÁLEZVARAS, 1999: 28). 
Sin embargo, y dado el objeto de este trabajo, un punto de partida razonable se sitúa en la reinterpretación de la gestión pública del territorio que dio pie al urbanismo como disciplina técnica a finales del siglo XIX. En ese momento, datamos el planteamiento del arquitecto Camille Sitte (1843-1903) con el que se mira la ciudad por primera vez como un continuo histórico que debe entenderse plenamente en su desarrollo morfológico y tipológico, con el fin de derivar reglas y modelos para el crecimiento de la ciudad moderna (BANDARÍn y VAN OERS, 2014: 44). El propio fenómeno de la ciudad jardín surgió como puesta en valor de las soluciones y paradigmas sobre la forma del espacio urbano, en el contexto de un espíritu renovador del concepto de urbe (GUERRAND, 2002: 18)

Esa visión despertó la valoración discrepante de los teóricos que preferían una visión transformadora de la ciudad y que décadas después acabó derivando en el Movimiento Moderno, uno de cuyos capítulos más significativos con relación a nuestro trabajo se corresponde con la arquitectura racionalista. Germinan entonces los dos polos encontrados en el tratamiento de la ciudad histórica que hoy tanto inciden en el tratamiento de los paisajes culturales urbanos.

La amplia historiografía sobre el patrimonio histórico se ha sintetizado (CAstillo, 2009: 29-37), a nuestro juicio con claridad didáctica, en varias fases primordiales: a). La etapa del monumentalismo, la descontextualización y el aislamiento del siglo XIX, a partir de la doctrina creada entre otros por Eugene Emmanuel Viollet-le-Duc y de John Ruskin; b). La etapa de superación del monumentalismo, en el que aparece el concepto de ambiente, durante la primera mitad del siglo xx, guiada en gran medida por la obra de Gustavo Giovannoni; c). La etapa de la ciudad histórica como ámbito de protección, incluyendo la instauración de la conservación integrada, durante la segunda mitad del siglo xx; y d). La etapa actual del territorio como ámbito patrimonial preferente, durante lo que llevamos del siglo XXI.

En este proceso, la segunda mitad del siglo $x x$ ha coincidido con una preocupación sobre estos entornos y sus valores, alcanzando cotas políticas en la escala nacional e internacional. Ello ha evidenciado la relevancia del tema en el desarrollo social y económico a nivel mundial. Es fácil recopilar el esfuerzo de países y entidades supranacionales en buscar estrategias comunes de conservación de estos entornos y del conjunto del patrimonio cultural mundial. Disponemos de compendios que han inventariado este fenómeno, exponiendo una revisión crítica institucional muy instructiva en esta lectura -por ejemplo, recomendamos el número monográfico de la revista Ciudades (Álvarez et al., 2002), así como RIVERA (2010) o BANDARÍn y VAN OERS (2014)-.

Aquí, la UNESCO ha jugado un papel estelar, promoviendo un sinfín de acontecimientos, cartas y resoluciones que ilustran la asimilación contemporánea del patrimonio cultural como referente del desarrollo en el territorio. Esta sucesión de documentos ha creado el corpus conceptual que hoy observamos en el marco legal sobre la conservación de los bienes y los paisajes en los que se emplazan (Carta de Gubbio, 1960, Recomendaciones de 1962 y 1968, la creación del Consejo Internacional de Monumentos y Sitios, ICOMOS 1964, la Recomendación de Nairobi, 1976, la Convención del Patrimonio Mundial Cultural y Natural, 1972, la Conferencias internacionales de Oslo, 1976, Machu Pichu, 1977, Granada, 1977, Quito, 1977, Washington, 1987, Xi'an, 2005, Quebec, 2008, La Valeta, 2011, Madrid, 2013). Incluso, a nivel de la Unión Europea han surgido hitos fundamentales en 
esta temática, tales como la Declaración de Amsterdam y la Carta Europea del Patrimonio Arquitectónico (1975) o el Convenio Europeo del Paisaje (Florencia, 2000).

Este corpus ha enriquecido su contenido, englobando variables fundamentales en nuestro objetivo, tales como el patrimonio histórico en sí mismo, los criterios de delimitación de los centros o paisajes históricos, su pluralidad, su integración en la ciudad o entorno territorial, la integración de los elementos del patrimonio cultural en la trama, su dinámica urbana específica, su impronta escénica, la rehabilitación y la planificación urbana, la vivienda, el comercio callejero, la seguridad ciudadana, el medio ambiente y los riesgos naturales, los espacios universitarios, las comunicaciones, los servicios, el turismo o el tejido económico. Son primordiales y comunes en la discusión de estas áreas urbanas sensibles y su relación con la ordenación del territorio (LozANo, 2013: 9).

Resultado de este proceso, los paisajes culturales urbanos se conciben como entes territoriales que socialmente son los más emblemáticos dentro de los conjuntos históricos (sin referirnos a la categoría de bien de interés cultural). Presentan un excepcional valor dentro del imaginario colectivo de los ciudadanos, por cuanto participan de la propia identidad territorial de la ciudad (ZÁRATE, 2010: 8). También, son los más difíciles de conservar por la complejidad de intereses que confluyen en ellos y que tienden a modificarlos constantemente.

Tal es así en el Archipiélago Canario que ha sido implementado por el Gobierno autonómico en la nueva Ley 11/2019, de 25 de abril, de Patrimonio Cultural de Canarias. Aunque su derivación jurídica es más concreta que el fin conceptual sobre el que reflexionamos, interesa subrayar la consideración del paisaje cultural como una categoría de bien de interés cultural. Lo define (art. 23) como lugar en el que confluyen bienes patrimoniales materiales e inmateriales, representativos de la evolución histórico-cultural, cuyo carácter sea resultado de la acción e interacción de factores naturales y humanos y, en su caso, con valores paisajísticos y ambientales, para convertirse en soporte de la identidad de una comunidad.

Esa concepción de lugar como expresión territorial es afín a la superación del hecho individual que tradicionalmente ha tenido el patrimonio histórico a través de sus enclaves, inmuebles o monumentos para trascender a una perspectiva integral. Es una zona o barrio de la ciudad que resulta de una estratificación histórica de valores y atributos culturales y naturales, para abarcar el contexto general del espacio urbano y su entorno geográfico... Este contexto general incluye otros rasgos del sitio, principalmente su topografía, geomorfología, hidrología y características naturales; su medio urbanizado, tanto histórico como contemporáneo; sus infraestructuras, tanto superficiales como subterráneas; sus espacios abiertos y jardines, la configuración de los usos del suelo y su organización espacial; las percepciones y relaciones visuales; y todos los demás elementos de la estructura urbana. También incluye los usos y valores sociales y culturales, los procesos económicos y los aspectos inmateriales del patrimonio en su relación con la diversidad y la identidad (Puntos 8 y 9 de la Recomendación de la UNESCO en París, 2011).

Esta vocación integral es crucial en la hipótesis de concebir Ciudad Jardín como paisaje urbano cultural. No necesariamente debe adscribirse a una figura jurídica de alcance territorial, sino que es una cualidad implícita en aquellos ámbitos cuya suma de características, valores y formas generan un espacio 
singular, emblemático o representativo de la identificación de Las Palmas de Gran Canaria.

\section{SÍNTESIS DE LA METODOLOGÍA}

Los resultados obtenidos son consecuencias de un trabajo en el que hemos combinado las técnicas comunes a la geografía histórica y la urbana, al análisis diacrónico del paisaje, al análisis de la ordenación urbanística y a los sistemas de información geográfica. Entonces, los mecanismos de observación de la estructura urbana en cada período, con los distintos elementos territoriales que la conforman, han guiado el proceso analítico y expositivo, incidiendo en su lectura evolutiva a lo largo de las fases de construcción de ese paisaje cultural. Compartimos la tesis de que cualquier elemento del pasado, en condiciones de proporcionar referencias sobre el escenario urbano y su forma escénica en etapas precedentes, los rasgos y pautas sociales que intervienen en los mismos y las condiciones que definen su realidad territorial en sus múltiples dimensiones (ambientales, económicas, culturales, geoestratégicas, de poblamiento, etc.) puede ser entendido como una fuente de investigación en si misma (Tosco, 2009: 96).

$\mathrm{Su}$ aplicación al caso seleccionado nos lleva a pensar en la utilidad de los contenidos administrativos, la disposición y caracterización de la propiedad del suelo, la distribución, agrupación y formalización de los edificios y la urbanización del espacio, los usos y actividades económicas, residenciales y de ocio, el comportamiento del medio ambiente afín a los rasgos de cada período; todo ello expuesto en la documentación escrita que se almacena en los archivos históricos, hemerotecas y fondos urbanísticos oficiales, en la documentación gráfica en forma de cartografías, proyectos de arquitectura y fondos de fotografía histórica y, ¿cómo no?, en la investigación ya realizada por otros compañeros.El uso de los planos y planes históricos ha sido fundamental para la percepción de lo acontecido durante la primera década del siglo $\mathrm{xx}$, mostrando en sus distintos formatos y rigores de escala una información valiosa sobre la configuración del ámbito. Se ha seleccionado con este objetivo los documentos históricos de Luis.F. López Echegarreta (1883), Laureano Arroyo (1898), Fernando Navarro (1911), Benito Chías (1914), Miguel Martín Fernández (1930), José Mª Pinto (1942), Secundino Zuazo (1951) y el contenido del Plan General de Ordenación Urbana (BOYER, 1962).

Vinculado a esta eficacia documental, la disponibilidad de la fotografía aérea gracias el inventario de la empresa pública GRAFCAN (a través del conocido Visor IDECanarias) $)^{1}$ permite con mayor detalle la continuidad de ese análisis para la segunda mitad del siglo xx hasta la actualidad, siendo igualmente una fuente imprescindible en este trabajo. En concreto, la ortofoto correspondiente al año 1954 y los vuelos desarrollados en los años 60 y décadas posteriores han ejercido esta función. Junto a ello, otros trabajos como el de las fotografías aéreas editadas por el CECAF ${ }^{2}$ (1949) y el AytoLPGC ${ }^{3}$ (1974) han completado la misma. Su lectura

1 GRAFCAN = Cartográfica de Canarias. Gobierno de Canarias. Visor de la Infraestructura de Datos Espaciales (IDECanarias)

2 CECAF = Centro Cartográfico del Ejército. Ministerio de Defensa. Vuelo de fotografía aérea en Las Palmas de Gran Canaria. 1949.

3 AytoLPGC $=$ Ayuntamiento de Las Palmas de Gran Canaria. Vuelo de fotografía aérea en Las Pal- 
ha combinado la interpretación de la realidad del momento y la ordenación del espacio urbano que, en muchos casos, perfilaría la forma del ámbito en décadas posteriores.

Por fortuna, este soporte informativo se ha completado con el bagaje bibliográfico sobre el proceso de construcción de la ciudad, constituyendo referencias básicas no sólo por su exhaustividad sino por la adecuación a los objetivos que perseguimos. Se corresponde con los trabajos de MARTín (2001), Herrera (1978), Morales (1995), Alemán (2008), junto a otros que diseccionan elementos concretos de gran relevancia en el objeto de esta investigación (Domínguez et al., 2009).

Los fondos documentales de planes de ordenación urbanística y proyectos sobre obras públicas o particulares que hemos podido recopilar de los expedientes disponibles en el Área de Urbanismo, Edificación y Sostenibilidad Ambiental del Ayuntamiento de Las Palmas de Gran Canaria o el Archivo Histórico Provincial de Las Palmas han sido de incuestionable utilidad en la observación de zonas o elementos concretos del paisaje cultural en Ciudad Jardín. En este sentido, el acceso al Fondo de Miguel Martín Fernández de la Torre gestionado por la Biblioteca de la Universidad de Las Palmas de Gran Canaria ha participado de ese bagaje. La hemeroteca aglutinada en el Archivo de Prensa Digital de Canarias (Jable. Biblioteca Universitaria de Universidad de Las Palmas de Gran Canaria) constituye otro apoyo impagable en la remonta a las fechas de investigación a los efectos de consultar la vida y los acontecimientos urbanos como referencia en la interpretación del paisaje de base histórica. Este compendio documental y bibliográfico ha sido integrado en una cartografía actual a los efectos del análisis pretendido para la situación de ese paisaje cultural en 2020. Para ello ha sido muy útil el uso de una aplicación de sistema de información geográfica (QGis) con la que se ha elaborado una base de datos de las parcelas y espacios públicos del ámbito, en la que hemos integrado la información de los fondos anteriores, los datos de la $\mathrm{DGC}^{4} \mathrm{y}$ los resultados del trabajo de campo.

De acuerdo a lo anterior, la delimitación del concepto de paisaje urbano cultural para el ámbito avanza con un lenguaje más científico en la aplicación de la metodología de análisis que desarrollamos en sendos trabajos realizados dentro de equipos multidisciplinares de los que resultaron el Plan Especial de Protección de Vegueta-Triana (Hernández et al, 2014) y el Plan Especial de Protección del Entorno de la Calle Perojo (Hernández et al, 2017); ambos, repositorios de una definición legal específica, de un volumen y una proporción superficial destacada de inmuebles y enclaves de interés arquitectónico, cultural, histórico o ambiental y de un entorno diferenciado por sus rasgos y cualidades.

Presentan una destacada impronta urbana, pues no sólo integra singularidades, sino vulnerabilidades, desequilibrios en su dinámica urbana preexistente, oportunidades y factores relacionados con la condición estratégica de estos espacios en la ciudad y la isla de Gran Canaria. Este concepto integral permitió respuestas y soluciones en la ordenación urbanística en los casos anteriores, que se observaron mediante tres escalas fundamentales:

- Una primera escala se remite a la identificación individual del inmueble, monumento o edificio. Resultaba de la relación entre la exposición de una pieza arquitectónica valorada por su presencia en un espacio determinado y por las

mas de Gran Canaria. 1974.

4 DGC $=$ Dirección General del Catastro. Sede Electrónica del Catastro. Ministerio de Hacienda. 
características de la formalización constructiva, las pautas socioculturales que están detrás de las mismas, los rasgos de estilo artístico-tipológico o los de representatividad. En este sentido, las actuaciones de rehabilitación, de reestructuración o de renovación constructiva debían tender al resalte de los concretos valores arquitectónicos e históricos, como elementos de interacción y valoración paisajística en el emplazamiento. Entonces, la catalogación y sus normas particulares jugaron un papel crucial.

- Una escala media se corresponde con el grupo de inmuebles o la manzana. Observa el componente de entorno cualificado que se genera a partir del efecto expositivo de un conjunto de inmuebles, conformando piezas espaciales singulares en un área, una calle o un frente edificado de manzana. El criterio conceptual resulta muy similar al anterior; es decir, la concreción del emplazamiento como valor como herramienta básica. Sin embargo, debía reforzarse con una puesta en valor mediante las determinaciones del plan en cuestión, en la que se distinguiera el potencial paisajístico del conjunto arquitectónico y su representación de los rasgos diferenciados o singulares de un entorno local concreto.

Dicha diferenciación adquiría especial relevancia en la adecuada integración del grupo de inmuebles en el ámbito circundante (usos permitidos, actuaciones de volumetrías, cubiertas, fachadas, espacio público anexo, etc.), tanto como enclaves de calidad específica del paisaje urbano como de fragilidad frente al dinamismo y renovación de las zonas aledañas.

- Y una tercera escala o general se refiere al conjunto del barrio o ámbito urbano diferenciado. La concentración de inmuebles y piezas urbanas de interés cultural en un barrio o parte destacada del mismo se traducía en la configuración de un paisaje cultural que presuponía en si mismo cualidades específicas y de representación de la ciudad consolidada por la urbanización. Su tratamiento paisajístico se traducía en una unidad territorial con rasgos, potencialidades, problemas y vulnerabilidad que confluyen en un ámbito de especial interés urbano cultural. Coincidimos en el objetivo de la presente investigación. Acogía, como hemos dicho, un valor expositivo en su condición de reservorio de un destacado número de manifestaciones arquitectónicas (estilos constructivos, formas, emplazamientos, elementos urbanos complementarios) y de patrimonio cultural (relaciones-pautas sociales, religiosas, económicas y políticas a lo largo del tiempo).

Esa cualidad se nutría, a su vez, del papel que juegan estos barrios en la configuración de la idiosincrasia de la ciudad como entidad territorial compleja. Se asociaba a desarrollos de forma urbana y arquitectónica que incluían una alta carga de identidad social y de singularidad escénica que resultaban de su proceso cronológico.

Sobre la base de esos criterios de escala de observación y definición del paisaje, proponemos aplicar en Ciudad Jardín su esquema metodológico desde una perspectiva integrada, en la que todo ingrediente tiene un papel imprescindible en su concepción como unidad territorial.

Es una metodología que superpone distintos aspectos del desarrollo urbano, en el que los componentes de valor o singularidad se ponen en relación con la situación actual y los dinamismos sociales, de usos del suelo, de movilidad, de residencia, de dotaciones y equipamientos, etc.

Dichos elementos espaciales distintivos son la proporción de inmuebles o enclaves con singularidades arquitectónicas y de patrimonio histórico, la 
existencia de bienes de interés cultural, como referentes con sus áreas de influencia en la zona que los circunda, la tipología constructiva y volumetría de fachadas, la continuidad-perspectiva del entorno (forma urbana y percepción de conjunto) y la presencia de elementos naturales y zonas verdes-parques singulares.

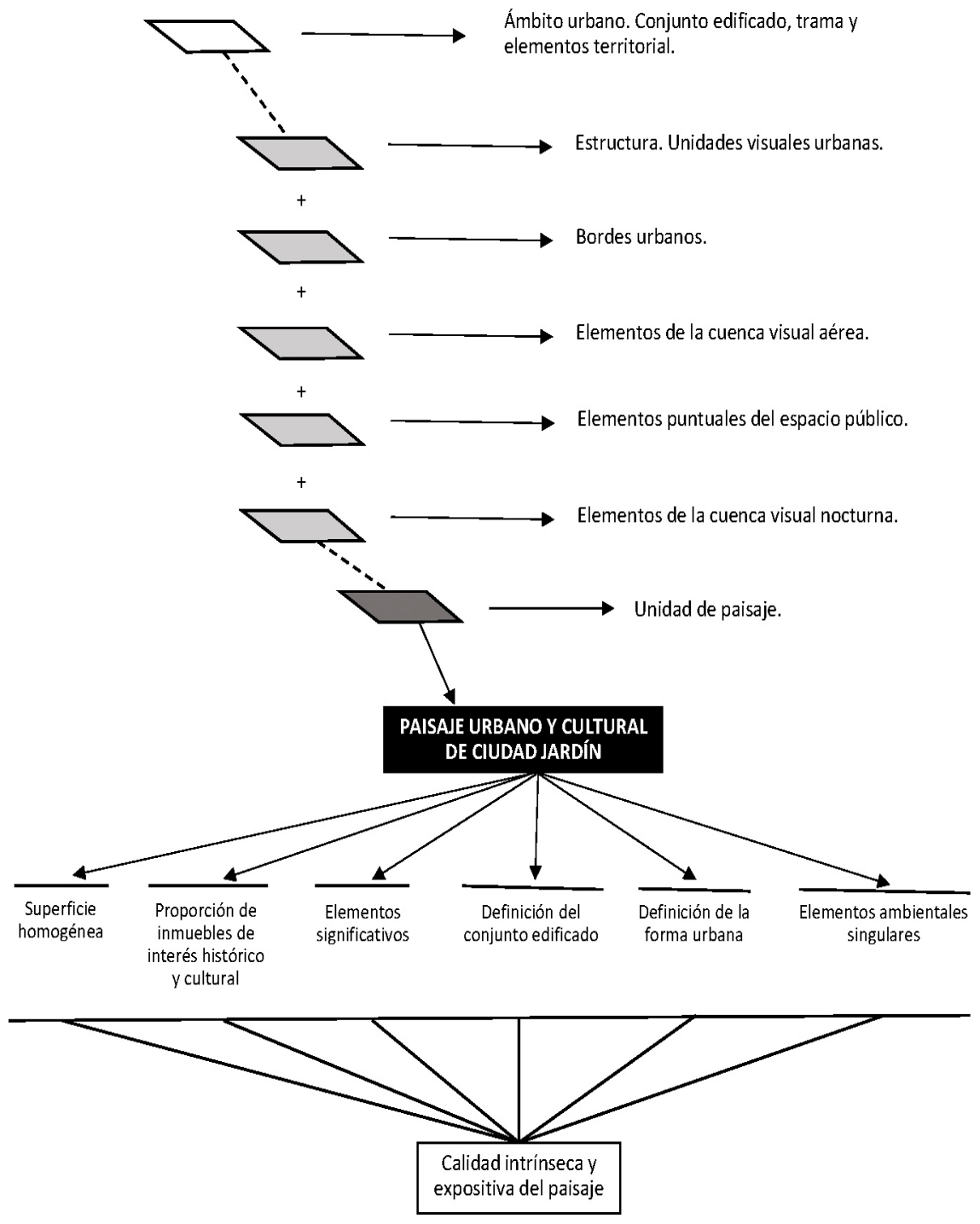

Figura 1. Elementos de configuración de un paisaje urbano cultural (Fuente. Hernández et al., 2017). 


\section{RESULTADOS}

\subsection{Proceso de formación urbana}

Ciudad Jardín está definido administrativamente como barrio sito entre el Túnel de Julio Luengo (que conduce a la Autovía GC-2) y el barrio de Las Alcaravaneras al Norte, el Paseo de Juan XxIII y el barrio de Lugo al Sur, el Paseo de Chil y las laderas de Altavista al Oeste y la Autovía GC-1 del Sur y Avenida Marítima al Este. Su emplazamiento se enmarca en la plataforma costera de la ciudad baja en Las Palmas de Gran Canaria, que de norte a sur se prolonga entre los riscos urbanizados que la separan de la Ciudad Alta y el frente marítimo de Levante o las estribaciones meridionales del complejo portuario de La Luz y Las Palmas.
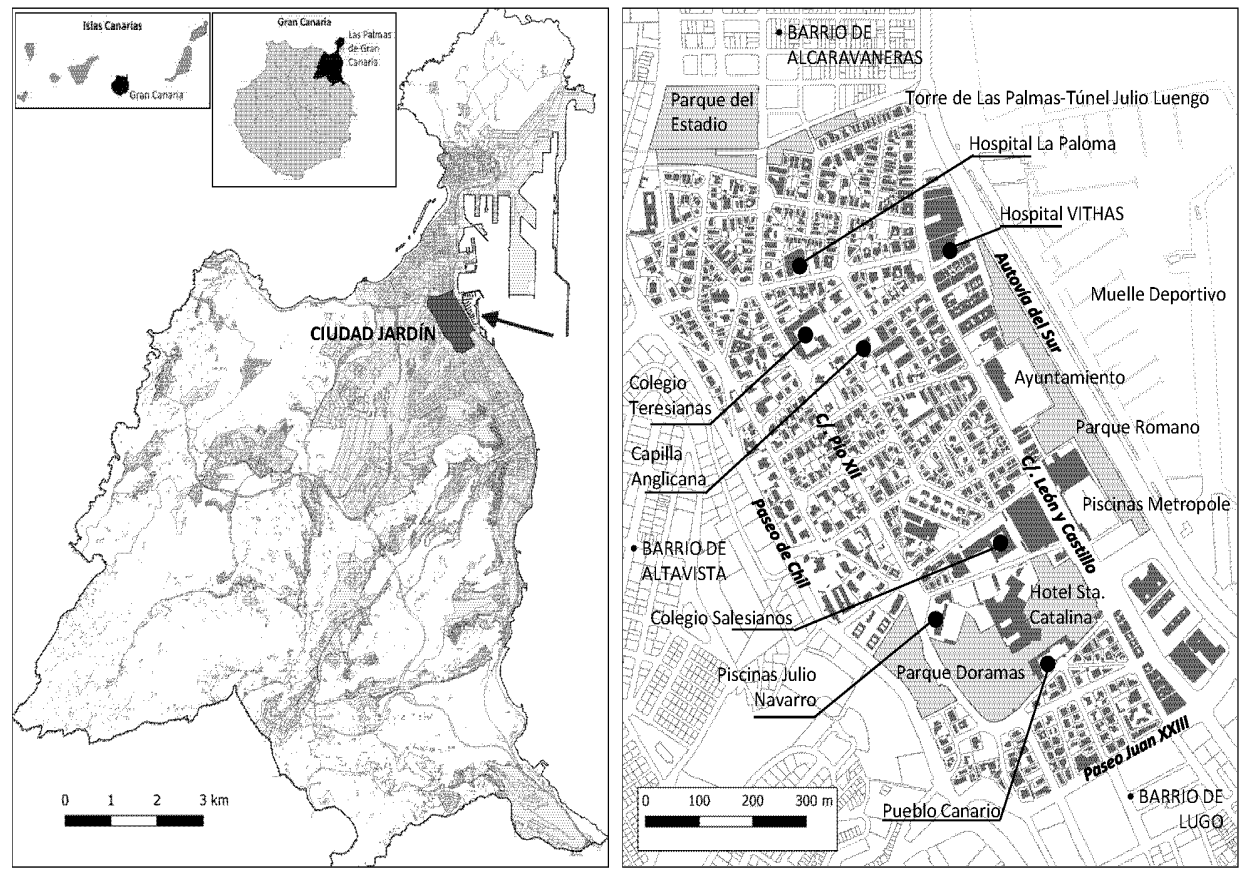

Figura 2. Emplazamiento y configuración general de Ciudad Jardín.

Su proceso de formación como paisaje cultural de la actual ciudad presenta un recorrido cronológico que se retrotrae a los finales del siglo XIX, cuando experimenta sucesivas transformaciones mediante el añadido o renovación de los elementos urbanos que van componiendo su forma. Podemos sintetizar esa sucesión en tres etapas básicas, cada una de las cuales tienen un papel directo en su actual condición de entidad espacial. 


\subsubsection{Etapa 1. Inicio de la ocupación de la Vega de Santa Catalina (hasta 1930)}

Su origen podemos situarlo en la aparición de las primeras viviendas durante los años del tránsito del siglo XIX al xx sobre la antigua Vega de Santa Catalina, ejemplificando el modelo tradicional anglosajón de formaciones residenciales en zonas periurbanas (MorAlEs, 1995: 90). En aquella ciudad que miraba hacia el norte tras rebasar la antigua Muralla de Las Palmas (ésta bordeaba el centro histórico) la zona de Lugo servía de borde urbano dejándose llevar por la inercia del crecimiento apoyado en la antigua Carretera del Puerto (hoy calle León y Castillo) (LÓPEZ, 1883). Tras dicho perímetro se extendía una extensa plataforma ocupada por fincas agrícolas sobre la prolongación del arenal y formación sedimentaria que conformaba el istmo dunar de Guanarteme (hoy ocupado por los barrios de Alcaravaneras, Santa Catalina y Guanarteme).

Durante aquellos años y tras las primeras licencias de chalets a finales de los 80 (MARTín, 2001: 359) se generó en sentido sur-norte un proceso espontáneo (AlEMÁn, 2008: 93) de localización de edificaciones dispersas que acompañaron a las fincas y fueron integrándose en aquel paisaje agrícola y costero. Apareció un dossier de hoteles, villas y baños medicinales sin otro criterio de ordenación urbana que la cercanía de la carretera. La anterior autora nos refiere un estímulo de connotaciones británicas (township) que giraban alrededor de las preferencias por el ocio, el esparcimiento y el deporte. Esta inercia y su impronta territorial eran claramente perceptibles en los últimos años de la centuria (ARROYO, 1898).
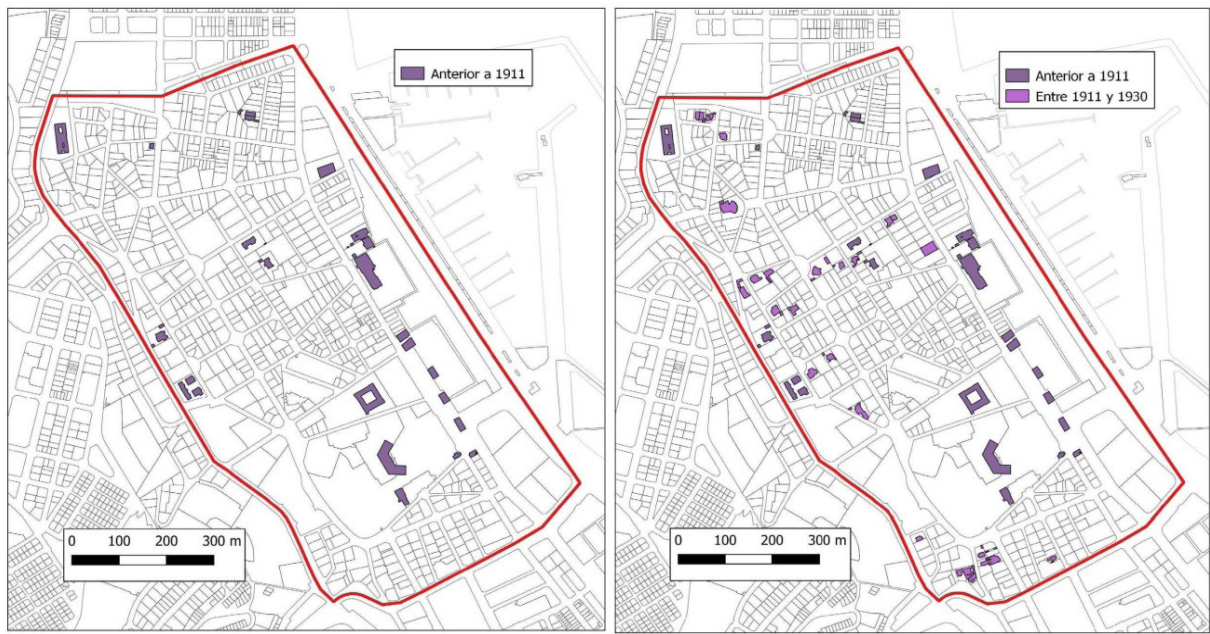

Figura 3. Ocupación edificatoria en los precedentes del barrio de Ciudad Jardín (hasta 1930) sobre el actual parcelario. Fuente: López (1883), Arroyo (1898), NAVArro (1911) y DGC (2019).

Acompañando a la histórica Ermita de Santa Catalina, el antiguo Hotel Santa Catalina (reconstruido en los años 50 del siglo xx), sus jardines, precedentes del hoy Parque Doramas, la alineación de elementos de esparcimiento litoral junto a 
la antigua playa de Santa Catalina, y algunas residencias dispersas en medio de los cultivos, representaban la apropiación del espacio.

Fue una modalidad de ocupación del suelo basada en unas construcciones singulares por su calidad y forma arquitectónica (barrio de los hoteles), con una distribución aislada en parcelas de huertas, de propiedad fundamentalmente británica, con apreciable superficie, y asociadas al uso del jardín y el arbolado como complemento indispensable a la función residencial (NAVARRO, 1911).

Aquellas pautas de residencia, fija o estacional, pusieron en valor los rasgos de calidez y reducidas precipitaciones del clima en Las Palmas de Gran Canaria. Presentaron una vocación por el vínculo entre el hábitat, el descanso, el ocio y el dinamismo cultural en el contexto de la ciudad del momento.

Al uso residencial se fue añadiendo durante los inicios de la anterior centuria una protourbanización del litoral, en la que se localizaron varios baños y zonas de esparcimiento en la antigua playa de Santa Catalina, sumándose al Hotel Santa Catalina y el Parque Doramas (éste último surgido como jardines hoteleros a fines del siglo XIX y adaptados como parque público en los años 20 y 30 del siglo xx). También aparecieron la Iglesia Anglicana (ya existía la Ermita de Santa Catalina), el precedente del actual Colegio Salesianos (Sagrado Corazón), el Beach Club, y el Hotel Metropole.

Como elemento estructurante, existió la vía costera o antigua Carretera del Puerto (hoy calle León y Castillo); a la cual se fueron añadiendo calles o caminos que descendían desde las laderas que hoy conocemos como Altavista (Baterías de Arenales y de Guanarteme) (Navarro, 1911). Estos recorridos transversales fueron denominándose en función de los grandes propietarios, sirviendo de acceso a sus fincas o huertas y permaneciendo en algunos casos en esa función conectora hasta la actualidad (Camino de Santa Catalina -actual calle Francisco González Díaz-, Camino del Colegio -calle Beethoven-, Camino de Blandy -calle Alejandro Hidalgo-, Camino de Dempster -calle Rafael Ramírez-).

Era un atisbo de trama que se superponía con similar formato a la fisiográfica (su relativo carácter llano se irregularizaba con los cauces y pequeñas elevaciones residuales del terreno). A la línea costera y la antigua Playa de Santa Catalina se le "conectaban" los referidos cauces de barranquillos que descendían desde la vertiente oriental y que hoy se sitúan bajo el espacio urbano consolidado (Barranquillo de Santa Catalina -hoy Barranquillo de Don Zoilo y Avda. Juan XXIII-, Barranquillo sin denominación -probable cauce de López Socas-, Barranquillo de Alcarabaneras -Avda de Escaleritas y calle Maestro Valle-).

Fue desarrollándose un conjunto residencial que acogió a aquellos pudientes que no quisieron integrarse en la ciudad consolidada, seleccionando un entorno de alta calidad ambiental en viviendas unifamiliares rodeadas de jardín (MORALES, 1995: 91-92). Pese a esas características y a la denominación actual del barrio, realmente ha derivado en un modelo difícil de asimilar al conocido paradigma de las garden cities (ciudad jardín) que planteó en esta misma época Ebenezer Howard como alternativa o sustitución de la ciudad densa. También es complejo adscribirlo al concepto más colectivo y organizado del garden suburb que se nos define para varias ciudades españolas coetáneas del supuesto que analizamos (DE TERÁN, 1999: 158) en el que subyace una componente de proceso colectivo impulsado desde esfuerzos protoinmobiliarios. En uno u otro caso, no es de extrañar que aquel crecimiento edificatorio en la entonces Vega de Santa Catalina derivase en estrategias planificadoras con vistas a dar un relativo orden, criterio y 
perspectiva a lo que se atisbaba como un barrio con múltiples facetas.

Ya en 1922 y antes de convertirse en uno de los grandes protagonistas del diseño de la ciudad de primera mitad del siglo xx, el arquitecto Miguel Martín Fernández de la Torre desarrolla el Plan de Ordenación de la ciudad (aprobado en 1930).

\subsubsection{Etapa 2. La definición del Ciudad Jardín histórico (1931-1955)}

El Plan diseñado por el anterior arquitecto supuso un hito fundamental en la configuración del barrio de Ciudad Jardín en su versión histórica. Ese plan vino a recoger las previsiones en cuanto al diseño urbano que se definió en proyectos parciales durante los años precedentes y no incidió en la definición volumétrica ni otros parámetros urbanísticos comunes en la actualidad (MirallaVE, 2009: 86). Ni siquiera persiguió el ideal del sistema ortogonal en la composición del espacio urbano que pretendía, tan recurrido en la ordenación de la ciudad del momento (CÁCERES, 1980: 57). Sí resolvió como nuevo objetivo en ese plan la trama viaria estructurante en toda la ciudad baja (CASARIEGO, 1987: 85).

En cualquier caso, el ámbito continuó el desarrollo de la ocupación edificatoria de la antigua Vega mediante la selección de nuevos estilos constructivos y la referencia de una trama heterogénea en la organización de manzanas y parcelas (de la que hemos heredado el plano actual del barrio). Se culminaba así la urbanización de la plataforma costera convirtiéndola en un continuo urbano de sur a norte entre el centro histórico hasta el Puerto, dando forma en gran medida a la actual ciudad baja.

Fueron dos los factores que acabarían marcando el dibujo urbano. De una parte, la reproyección e inicio constructivo del Paseo de Chil (tras varios intentos en etapas precedentes), el cual se convertiría en una vía interior estructurante del crecimiento de este ámbito en paralelo a la antigua Carretera del Puerto. De otra, la coincidencia en la materialización de estas determinaciones urbanísticas con las pautas constructivas propias de la arquitectura racionalista y regionalista, las cuales presentarían una gran impronta en la configuración del paisaje cultural que hoy conocemos (MARTín, 2001: 394) y conforman una representación obligada del patrimonio arquitectónico de la ciudad.

La mayoría de las viviendas reproducían las condiciones de estilismo arquitectónico y de asociación a la zona verde, persiguiendo un paisaje atractivo y en cierto modo naturalista. Se dio rienda suelta a las formas racionalistas y regionalistas. 


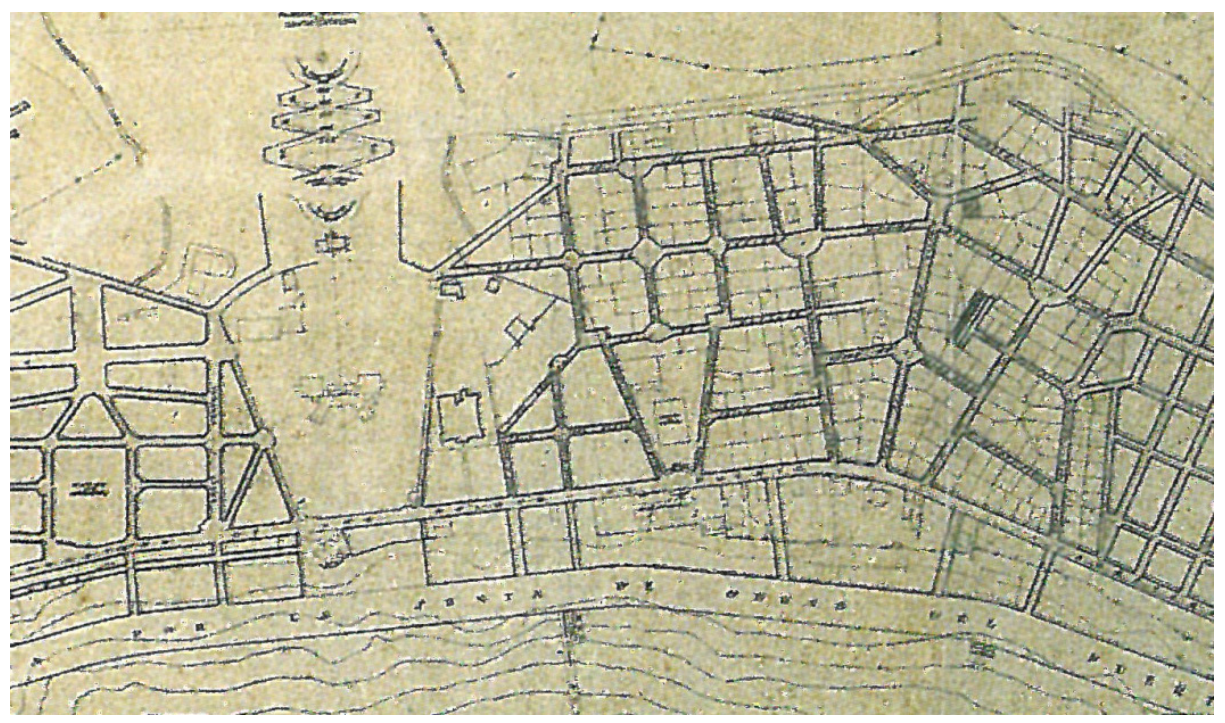

Figura 4. Extracto de la planificación prevista por Miguel Martín Fernández de la Torre. Fuente: AytoLPGC. Plano de Las Palmas, Alcaravaneras, Santa Catalina y Las Canteras

(1922-1930).

Estas pautas constructivas y de espacio colectivo reproducían los objetivos de estilismo arquitectónico, calidad del entorno, confort y tranquilidad, elitismo social de influencia y protagonismo europeo, sobre todo británico. Fue ampliándose el tejido residencial y el volumen demográfico tal como se había previsto, proceso en el que cada vez participó más la burguesía local atraída por una zona residencial más atractiva que los restantes barrios.

Junto a este tejido residencial, Ciudad Jardín consolidó el papel en la oferta turística de la ciudad que ya arrastraba desde el período anterior, conformándose en un enclave competidor al del centro histórico de Vegueta-Triana. No cabe duda de que la calidad medioambiental y paisajística, la cercanía del litoral y la función de balneario y la influencia noreuropea en el concepto del ocio motivaron esta relevancia. Junto al histórico Hotel Santa Catalina, se mantuvieron activos al final del período el del Metropole (actual Ayuntamiento), el Atlántico o el Bellavista. 
Guillermo Morales Matos, Santiago Hernández Torres y María Yazmina Lozano Mas

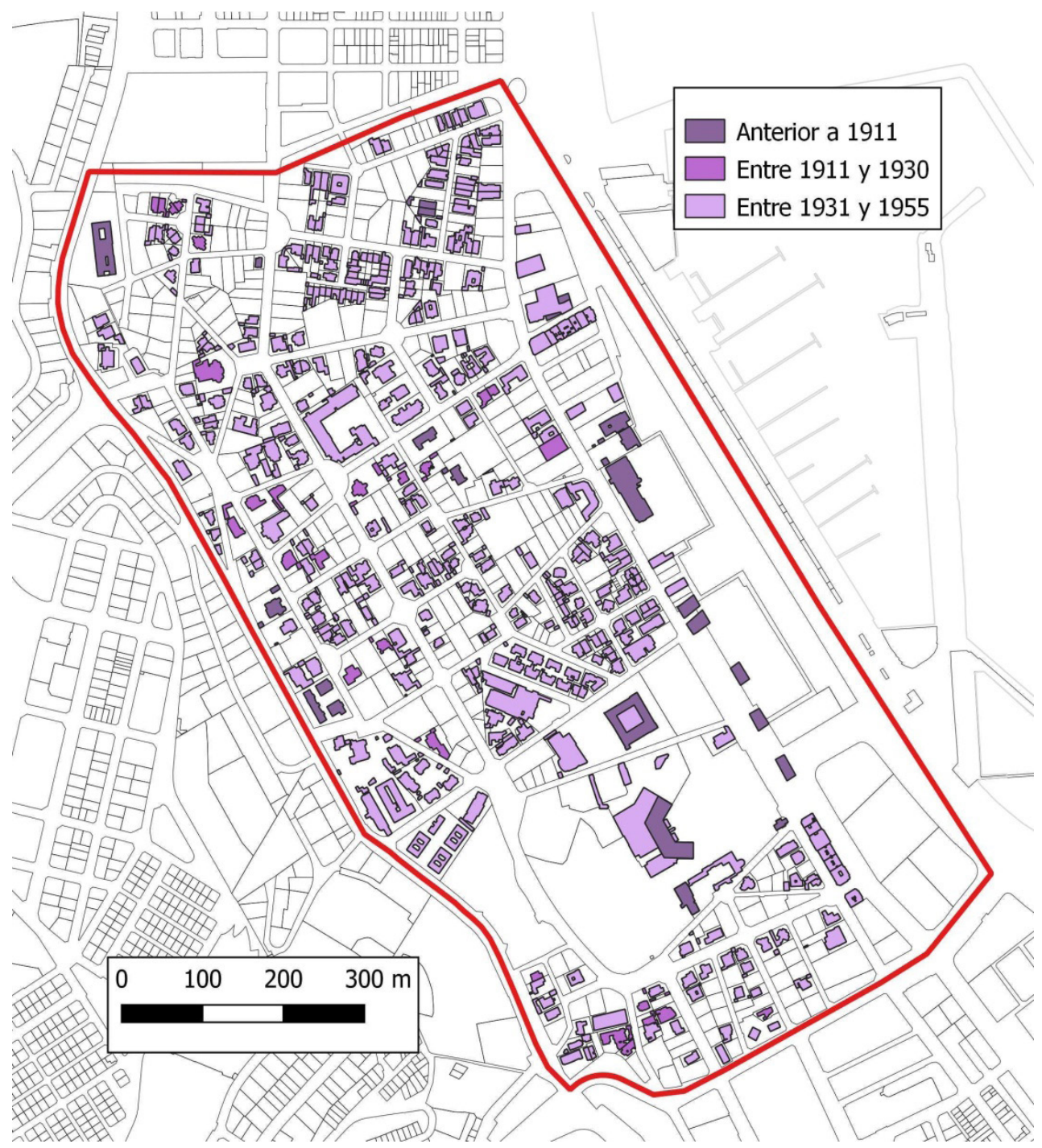

Figura 5. Ocupación edificatoria en los precedentes del barrio de Ciudad Jardín (19311955) sobre el actual parcelario. Fuente: Ortofoto de 1954 de GRAFCAN y DGC (2019).

La aparición del Pueblo Canario se convertiría en un emblema en este sentido, trascendiendo su emplazamiento a la imagen turística del conjunto de la ciudad y del Archipiélago como hito significativo de la arquitectura regionalista y neocanaria (GAGO, 2000: 131). La conservación de la infraestructura de balneario en el litoral, incluyendo la fuente de baños minerales en el precedente del Hospital de Santa Catalina, se completó con la conversión en parque público el actual 
Doramas y varios equipamientos tenísticos (Hotel Santa Catalina, C/. León y Castillo, etc.) y el pequeño campo de golf de Altavista (desaparecido a mediados del siglo).

Estos rasgos definieron la condición de Ciudad Jardín como uno de los principales centros del patrimonio cultural y arquitectónico de Las Palmas de Gran Canaria, compitiendo en este sentido con el propio centro histórico (MARTíN, 2001: 113; HERRERA, 1978: 343).

Su desarrollo fue poco alterado en el Plano de Secundino Zuazo (1944), excepto en la configuración de las manzanas costeras (antecedente de la edificación en bloque actualmente predominante) que alteró la fisonomía y sustituyó los usos entre la antigua Carretera del Puerto y el mar.

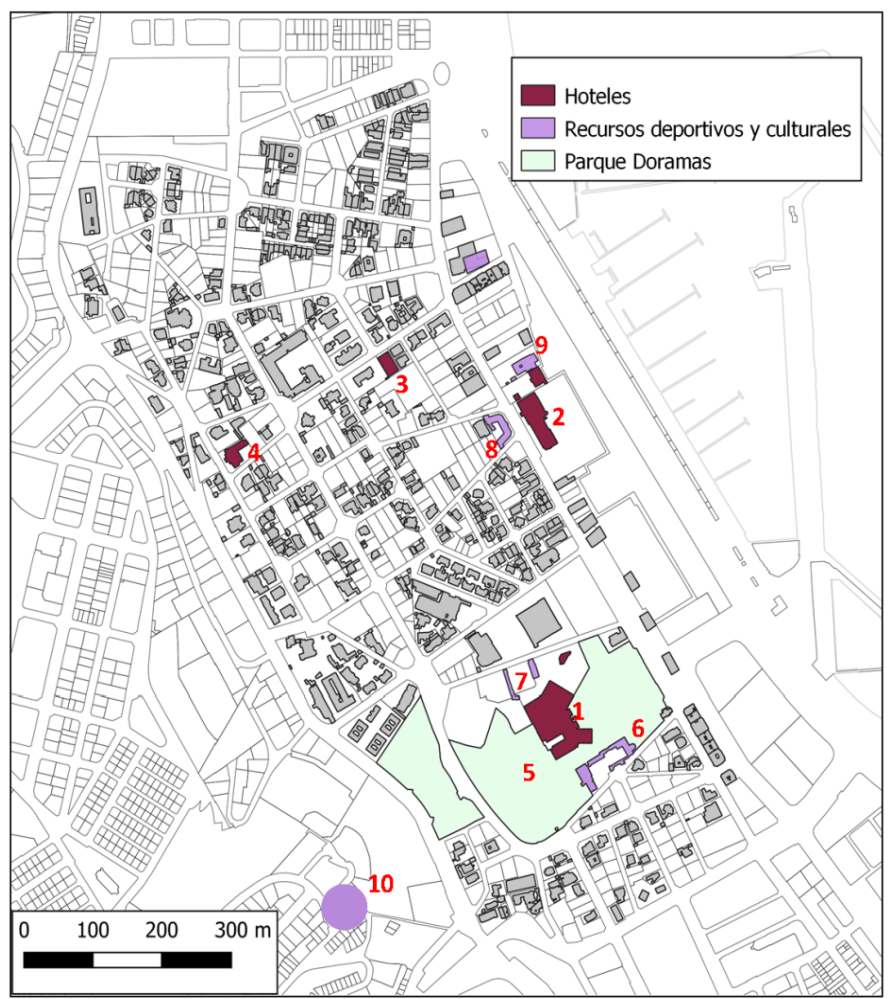

1. Hotel Santa Catalina

2. Hotel Metropole

3. Hotel Bellavista

4. Hotel Atlántico

5. Parque Doramas

6. Pueblo Canario

7. Club de tenis

8. Club de tenis

9. British Club

10. Campo de golf

Figura 6. Oferta turística en la Ciudad Jardín durante primera mitad del siglo Xx. Fuente: Ortofoto de 1954 de GRAFCAN y DGC (2019). 


\subsubsection{Etapa 3. La adaptación a la ciudad contemporánea}

A partir de los años 60 ese conjunto urbano iniciaría un proceso de adaptación a los esquemas del boom expansivo y terciarización del tejido urbano de la ciudad que se desarrollaría durante varias décadas y tendría consecuencias en la formalización singular del barrio. La aparición del Plan General de Ordenación Urbana de Las Palmas de Gran Canaria (1962), en su relativa sencillez normativa, introduce varias potencialidades que acabarían reformulando la forma urbana de Ciudad Jardín durante las siguientes décadas.

De una parte, una apreciable libertad para la configuración del tejido parcelario tuvo como resultado una atomización de la propiedad multiplicando la densidad de las fincas, reduciendo casi a la mínima expresión la superficie de las mismas y, con ello, incentivando la implantación de viviendas y otros usos edificados. El factor acelerante de este proceso fue la paralela densificación de la trama viaria y la accesibilidad interior del área, lo cual sólo tuvo que aprovechar la red estructurante prevista en el Plan de los años 30. Es un fenómeno que ya hemos observado en otros casos españoles (ALvARGONZÁlez, 1999: 75) y de esta misma ciudad (SOBRAL, 1995).

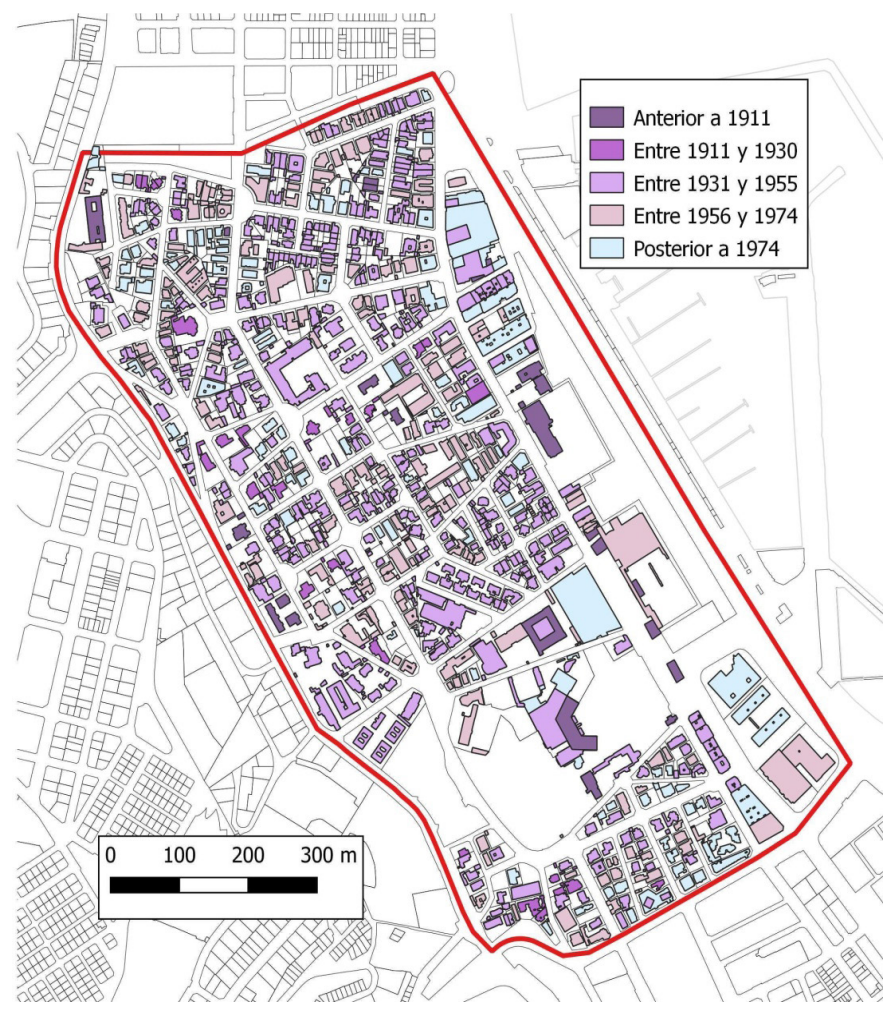

Figura 7. Ocupación edificatoria desde mediados del siglo XX sobre el actual parcelario. Fuente: Ortofoto de 1954 de GRAFCAN; Ortofoto de 1974 del AytoLPGC y DGC (2019). 
De otra parte, los parámetros constructivos, en unos casos, y la falta de mecanismos de control, en otros, facilitaron la diversificación de los estilos constructivos que bajo el paraguas de la modernidad sustituyó las formas preexistentes (hoy tan valoradas). Se pasó a seleccionar formatos más pragmáticos y adaptados al confort residencial y urbano del momento. Fue una barra libre que contaminó la rica herencia, proliferando nuevos materiales, gustos cromáticos, ampliaciones y añadidos constructivos o, de modo más drástico aún, la sustitución por diseños contemporáneos.

La prolongación de la Ciudad del Mar, con sus volumetrías en torres en el espacio entre la calle León y Castillo y la Avenida Marítima, distorsionó íntegramente la relación con el mar, no sólo por el añadido estructural y la sustitución de la antigua línea marítima sino por la generación de una pantalla paisajística sólo abierta por el Hotel Metropole (ahora Oficinas Municipales), el Parque Romano y hasta cierto punto el complejo deportivo del Metropole.

La renovación en los barrios adyacentes (Alcaravaneras, al norte, Lugo, al sur, la Cornisa, al Oeste, y el expuesto conjunto en torres en el margen costero) fueron fieles compañeros de esta transformación. Los inicios del siglo XXI se encontraron con un barrio en crisis de identidad funcional y tensiones entre los rasgos heredados como barrio de origen residencial y nuevas oportunidades emanadas de sus cualidades, su localización en la ciudad baja, o su accesibilidad.

\subsection{Los rasgos definitorios del paisaje cultural urbano}

La formación y crecimiento de Ciudad Jardín ha conservado en estas primeras décadas del siglo XXI un conjunto de rasgos que lo distinguen en el contexto de Las Palmas de Gran Canaria y del restante Archipiélago Canario como una modalidad de paisaje urbano cultural, dotándole de personalidad propia, de valor como referencia del territorio y su memoria geográfica y de especificidad frente a otros espacios históricos de la ciudad, del sistema de asentamientos de la isla o de las áreas rurales.

El desarrollo cronológico que sintetizamos en este cuarto apartado nos sirve de base para demostrar la justificación de esta hipótesis a partir del modelo conceptual que se propuso en este mismo trabajo y se grafió en la Figura 1.

La concreción en la modalidad tradicional en estos barrios incorpora una noción de espacio con unas condiciones morfológicas y paisajísticas diferenciadas del resto de la ciudad; condiciones que resultan de una conciencia social conservada a lo largo del tiempo (identidad) y de una materialización histórica con arreglo a unas pautas culturales y económicas en cada momento. Son un espacio social integrado con una evidente delimitación en la trama urbana, con una herencia polifuncional y una idiosincrasia cultural que, en conjunto, participa con un papel especifico en el dinamismo contemporáneo (SolanA et al., 2003: 27).

\subsubsection{Una superficie homogénea y una forma urbana diferenciada de su entorno}

$\mathrm{Su}$ evolución ha perfilado la configuración del barrio de acuerdo con los criterios, pautas y estrategias de cada período temporal; evolución que ha permitido conservar su fisonomía tradicional en el contexto una ciudad muy 
transformada. Este tipo de características conduce a unidades urbanas bien diferenciadas en su forma, distinguiendo las que podemos considerar como parte del casco antiguo, de las diversas modalidades de ensanche, de la variedad de ejemplos de autoconstrucción, o del fenómeno de ciudad jardín (CAPEL, 2002).

Ciñéndonos al área más relacionada con el ámbito de estudio la distinción es evidente. El dinamismo de la denominada ciudad baja muestra una caracterización morfológica de los barrios circundantes con diferencias sustanciales en la tipología edificatoria, en la modalidad de organización en la trama, o en las características sociales.

En nuestro caso, existe un predominio de la formación en baja densidad constructiva (parcelas de superficie superior a $500 \mathrm{~m}^{2}$ ) y limitada volumetría (2-4 plantas) que se rompe en el frente costero con una modalidad en manzana cerrada y casas terreras, con presencia de construcciones de apreciable altura. En parte, podríamos considerarla ajena a este barrio en su impronta paisajística, aunque forme parte del mismo a nivel administrativo. Excluyendo esta zona, la homogeneidad que deviene de una arquitectura de chalets, villas e inmuebles con estilos constructivos históricos y algunas formas contemporáneas y el acompañamiento aún presente del arbolado y el jardín, dibujan el escenario.

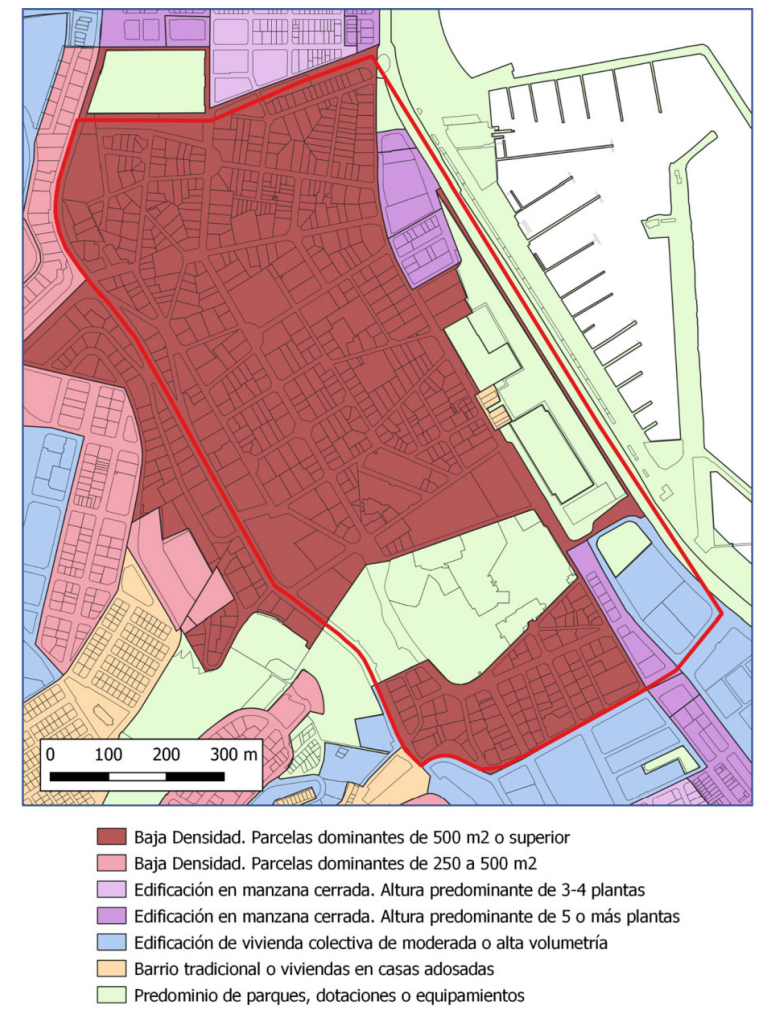

Figura 8. Distintos tipos morfológicos de Ciudad Jardín respecto a su entorno. Fuente. Elaboración propia. 
Al norte y al sur del mismo, los barrios de Alcaravaneras y de Lugo, respectivamente, se organizan mediante una relativa disposición ortogonal, a modo de manzanas cerradas, que integra una amalgama de tipologías edificatorias de predominante carácter contemporáneo. Y ello no sólo se corresponde con el estilo o la estética arquitectónica. Participan también los continuos cambios de volumetría en los que por observar algún patrón reflejan una altura destacada en las calles principales (6-7 plantas a lo largo de Tomás Morales, Galicia que vienen a prolongar en ambos sentidos el efecto estructurante de nuestra calle Pío XII, o Presidente Alvear y Luis Doreste Silva que hacen lo propio con el tramo de la calle León y Castillo. Hacia el interior, y con mayores contrastes, es posible distinguir una mayor presencia de las 3 o 4 alturas. Salvo la zona verde, representada en algún parque o plaza local, la aportación botánica a la escena urbana es inexistente o restringida al borde de las calles de mayor rango.

Al Oeste, las laderas de La Cornisa-Altavista reflejan una ocupación no sólo diferenciada por el tránsito altitudinal sino en una manifestación contemporánea de la disposición en baja densidad (mediante una modalidad de superficie parcelaria menor de $250 \mathrm{~m}^{2}$ ) y con tipologías distintas a las históricas de la primera década del siglo $x x$.

4.2.2. Un conjunto edificado de especial interés histórico y arquitectónico, una alta proporción de parcelas protegidas, y la presencia de singularidades culturales y ambientales

Es un barrio que presenta un origen relativamente histórico en el contexto local (primeras décadas del siglo xx) y un proceso de consolidación que ha tenido como resultado una herencia apreciable en forma de patrimonio arquitectónico. Su evolución temporal ha perfilado el entorno de acuerdo con los criterios, pautas y estrategias de cada período; proceso que ha permitido conservar su fisonomía tradicional en el contexto, una ciudad muy transformada.

De una parte, el historicismo con buenas dosis del eclecticismo de influencia centro y noreuropea está detrás de la distribución de un apreciable elenco de villas, de chalets históricos, de house o de cottage (AlEMÁn, 2008: 117) con mayor o menos acompañamiento de jardines y que presentan una impronta singular en los rincones de cada calle o esquina en que se emplazan. Una de sus reminiscencias más identificativas son los torreones o miradores, los cuales tienen en Ciudad Jardín uno de sus principales muestrarios (Domínguez et al., 2009: 151).

De otra y con cierto retraso, a partir de los años 30, proliferaron los ejemplos constructivos basados en las preferencias regionalistas, como conjunto de pautas que combinan los objetivos de la arquitectura moderna y funcional con las reminiscencias de lo local o lo canario. Bien es verdad que las preferencias compositivas fueron muy variadas $\mathrm{y}$, por decirlo de alguna manera, cada arquitecto tenía su librillo (OJEDA, 2011: 288). Sin menospreciar al resto de proyectos, los hitos más significativos de este capítulo suelen considerarse en el conjunto arquitectónico del Pueblo Canario y en el Hotel Santa Catalina (GAGO, 2000: 131).

Y un tercer grupo significativo se corresponde con el tejido arquitectónico racionalista, cuya implantación en la ciudad deriva en uno de los grandes capítulos del patrimonio cultural de Las Palmas de Gran Canaria. Ciudad Jardín es un enclave destacado a nivel proporcional y de singularidad de los inmuebles 
en la localización de esa producción arquitectónica. El referido Miguel Martín Fernández de la Torre (urbanista en el plan aprobado en 1930) fue autor de decenas de esas construcciones, seleccionando a partir de unos criterios básicos comunes diversas soluciones en función de la localización y los objetivos de los promotores. Incluso, algunos autores lo subrayan como la gran obra total en la aportación del diseñador al movimiento moderno (RodRíGUEZ y PETER, 2017: 100).

Atendiendo a nuestra lectura geográfica, un recorrido por sus calles nos genera un efecto de escenario singular a partir de la prevalencia de inmuebles exentos, la estética local de su presencia en esquina o en parcelas de baja densidad, el acompañamiento selectivo del jardín, la reducida altura volumétrica de los inmuebles, la visión vanguardista y futurista de la edificación en su contexto cronológico con la funcionalidad en la selección de los elementos compositivos de materiales industriales (barandillas metálicas, herrajes, ventanas, puertas), la cubierta plana, la limpieza o falta de ornamentación de las paredes y fachadas, la tipología y forma de los huecos, la horizontalidad o linealidad prevalente en su alzado, los tramos o esquinas semicirculares, etc., como banderas.

$\mathrm{Su}$ consecuencia cualitativa se refleja en la configuración del paisaje y su condición cultural, explicando la integración de una destacada proporción de estos inmuebles en el Catálogo Municipal de Protección de Las Palmas de Gran Canaria, atendiendo a su especial interés histórico y arquitectónico (178 parcelas en 103 registros o fichas).

Su número es relevante para un ámbito que no ha sido considerado Bien de Interés Cultural con la categoría de Conjunto Histórico, como en el centro de Vegueta, Triana, calle Perojo o La Mayordomía de Tamaraceite.

Pese a ello, se localizan dos bienes de interés cultural con la categoría de monumento (Iglesia Anglicana y el Pueblo Canario) como referencias de la máxima significación legal en la condición del patrimonio como capítulo de interés general en la sociedad urbana. 
La Ciudad Jardín de Las Palmas de Gran Canaria como paisaje cultural urbano
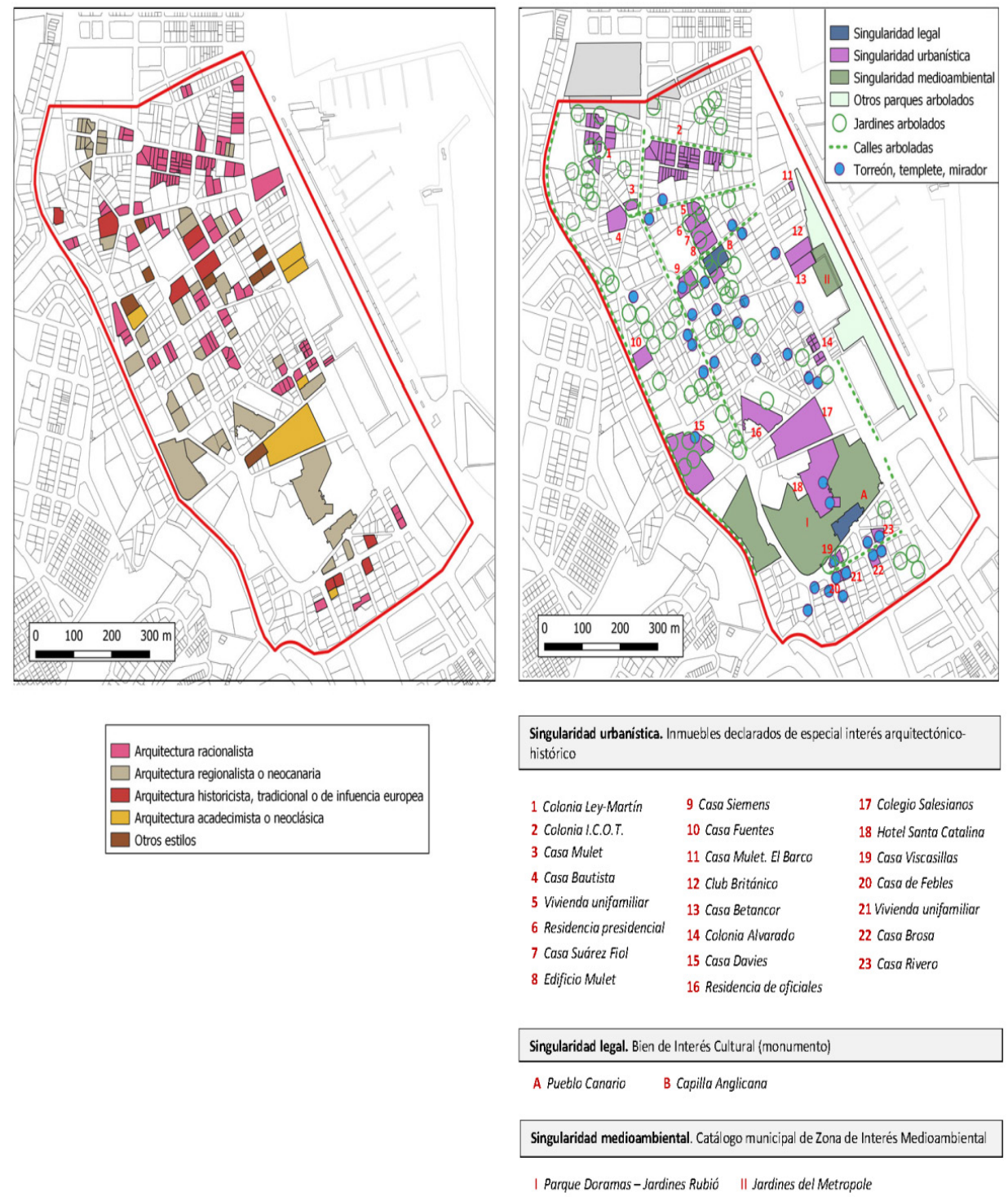

Figura 9. Estilos arquitectónicos en los inmuebles definidos como patrimonio cultural, en la izquierda, y singularidades existentes en el ámbito, en la derecha. Fuente: Elaboración propia a partir del Catálogo Municipal de Protección editado por el AytoLPGC, 2012 y

DOMínguez et al. (2009).

Esta perspectiva jurídica se completa con la localización de una veintena de piezas para las que por sus cualidades se le considera un grado de protección 
«integral» (el máximo nivel en este objeto jurídico), incluyendo el emblemático Hotel Santa Catalina. La aportación natural a este conjunto no es nada desdeñable.

Es el caso de los jardines del Metropole o el Parque Doramas definidos urbanísticamente como referencias del patrimonio natural y paisajístico del municipio (Zona de Interés Medioambiental) en base a su implicación en la memoria histórica y social de la urbe, y a la rica biodiversidad que acoge.

Aparte de esta significación "oficial», un ingrediente básico (la zona verde privada) conserva su presencia en el ámbito, sustituyéndose algunos emplazamientos históricos por otros y concluyéndose incluso una superficie actual más extensa que la existente en los años 50. Cuando la parcela es amplia (más de $750 \mathrm{~m}^{2}$ ), la presencia arbolada por su porte y número de individuos presenta una impronta definitoria de la perspectiva del entorno, de la calle o de zonas concretas. La riqueza de especies heredada o introducida en esta fase contemporánea es significativa, siendo bastante comunes la palmera canaria, las variedades de Ficus, de pimenteros (Schinus molle, Schinus terebinthifolius), flamboyanes (Delonix regia), dragos (Dracaena draco), etc, se completan con masas arbustivas con una incontable biodiversidad.

Como rasgo negativo en estos espacios libres interiores, los esquemas funcionales sobrevenidos en estas décadas han contaminado este rasgo ambiental con el acompañamiento de los garajes exentos a la vivienda, las piscinas y demás complementos de la moda de esos momentos.

Por otra parte, el espacio público de las calles observa una destacada presencia natural con una proliferación de palmeras (con apreciable predilección de la Phoenix canariensis) y laureles de indias (Ficus microcarpa). En algún caso, se localizan individuos únicos de determinadas especies (ejemplo de los neem de la India en Pío XII como únicos ejemplares de Azadirachta indica en toda la ciudad baja). Su disposición a lo largo de ambos márgenes de la calzada, y como hito en muchas esquinas, marcan la propia configuración escénica de las mismas. Ejemplos significativos pueden seleccionarse en las vías de recorrido norte-sur (Paseo de Chil, García Castrillo, Pío XII) o en la mayor parte de sus transversales de Este a Oeste (calles Hermanos de la Torre, Maestro Valle, Rafael Ramírez o Paseo Madrid).

Otra modalidad de aportación botánica se corresponde con el Parque Romano y el Parque Doramas. En el primero, la homogeneidad del recorrido longitudinal de flamboyanes y palmeras washingtonias se enriquece con la apreciable variedad en los Jardines del Metropole (trasera del Ayuntamiento) y la zona de juegos cercana (palmeras canarias, dragos, laureles y otros ficus). En el segundo, su carácter histórico y su condición de parque estratégico en el sistema de espacios libres de la ciudad lo han consolidado como jardín botánico a modo de aula al aire libre de la jardinería urbana. Un inventario reciente del Servicio de Parques y Jardines del Ayuntamiento concluyó un grupo de varias decenas de especies, con una riqueza biótica vegetal y un acompañamiento de avifauna que lo convierten en elemento definitorio del ámbito, no sólo en términos de proporción superficial sino de cualidades compositivas (diseño histórico) y naturales.

Como es lógico la presencia de vegetación no es en sí misma una singularidad, en tanto que buena parte de los barrios de la ciudad acoge alguna representación de este elemento natural. La singularidad en este caso deviene de la impronta paisajística, la alta densidad dentro de la trama y la riqueza botánica más allá de la específica función como zona verde. Este fenómeno es aún más claro cuando 
observamos las características y participación de la vegetación en los barrios circundantes y en el conjunto de la ciudad baja, con un resultado espacial y ambiental menos perceptible.

Entonces, la combinación de una destacada presencia de jardines privados y las características ambientales del espacio público representado en las calles y parques constituyen un rasgo definitorio de Ciudad Jardín como paisaje urbano con marcada componente cultural.

\subsection{Tensiones y oportunidades en la gestión del paisaje urbano en Ciudad Jardín}

Ciudad Jardín se muestra hoy en día como como una entidad específica en el puzle funcional, social y paisajístico de toda urbe que se corresponde con su condición de barrio tradicional que ya planteamos en para otras zonas de la ciudad (HERNÁNDEZ, Ginés y LOZANO, 2016), a lo cual sumamos su impronta física y cualitativa como paisaje urbano cultural.

La concreción en la modalidad tradicional incorpora una noción de espacio con unas condiciones morfológicas y paisajísticas diferenciadas del resto de la ciudad; condiciones que resultan de una conciencia social conservada a lo largo del tiempo (identidad) y de una materialización histórica con arreglo a unas pautas culturales y económicas en cada momento.

Pese a la relativa continuidad de la trama en su conjunto, la constante renovación en las pautas de ocupación residenciales y restantes usos y la sucesión de cambios formales en los inmuebles y su impronta paisajística dejó en el camino un buen número de testimonios arquitectónicos de aquellas primeras décadas.

TABLA 1

Distribución de la superficie parcelaria en Ciudad Jardín según su uso en 1995 y 2020

\begin{tabular}{|l|c|c|c|c|}
\hline USOS & $\mathbf{1 9 9 5}$ & $\%$ & $\mathbf{2 0 2 0}$ & $\%$ \\
\hline Uso residencial & 305.843 & 53,17 & 276.164 & 48,01 \\
\hline Usos de dotaciones y equipamientos & 131.929 & 22,93 & 118.631 & 20,57 \\
\hline Educativo & 38.060 & 6,62 & 44.691 & 7,77 \\
\hline Sanitario y servicios de salud & 9.777 & 1,70 & 12.533 & 2,18 \\
\hline Deportivo & 41.536 & 7,22 & 21.171 & 3,68 \\
\hline Cultural & 6.715 & 1,17 & 6.204 & 1,08 \\
\hline Administración y sedes oficiales & 15.016 & 2,61 & 12.937 & 2,25 \\
\hline Religioso & 2.185 & 0,38 & 2.185 & 0,38 \\
\hline Militar, incluida residencia & 13.343 & 2,32 & 13.343 & 2,32 \\
\hline Comisaría de Las Palmas & 5.297 & 0,92 & 5.297 & 0,92 \\
\hline Usos terciarios & 27.325 & 4,75 & 40.880 & 7,10 \\
\hline Alojamiento turístico & 9.866 & 1,72 & 16.778 & 2,92 \\
\hline Comercio, restauración y superficies comerciales & 4.522 & 0,79 & 3.894 & 0,68 \\
\hline
\end{tabular}


Guillermo Morales Matos, Santiago Hernández Torres y María Yazmina Lozano Mas

\begin{tabular}{|c|c|c|c|c|}
\hline Oficinas, servicios, colegios profesionales & 11.277 & 1,96 & 18.548 & 3,22 \\
\hline Estación de servicios & 1.660 & 0,29 & 1.660 & 0,29 \\
\hline Espacios públicos abiertos & 79.173 & 13,76 & 102.525 & 17,82 \\
\hline Parques & 71.613 & 12,45 & 94.965 & 16,51 \\
\hline Otros espacios libres & 7.560 & 1,31 & 7.560 & 1,31 \\
\hline Usos mixtos & 30.977 & 5,28 & 37.317 & 6,49 \\
\hline Residencial con oficinas, servicios y similar & 29.344 & 5,10 & 29.344 & 5,10 \\
\hline Residencial con uso sanitario y servicios de salud & 1.633 & 0,28 & 1.930 & 0,34 \\
\hline $\begin{array}{l}\text { Educativo con superficie comercial en planta baja } \\
\text { parcial }\end{array}$ & 0 & 0,00 & 6.043 & 1,05 \\
\hline TOTAL DEL ÁMBITO & 575.247 & 100,00 & 575.247 & 100,00 \\
\hline
\end{tabular}

$\left(^{*}\right)$ El viario es el mismo en ambos años, experimentando actuaciones de mejora y reurbanización entre una fecha y otra. Fuente. Elaboración propia y Morales (1995).

La condición de área residencial sigue siendo predominante. Sin embargo, la segunda mitad del siglo $x x$ ha coincidido con un crecimiento de los usos de dotaciones y equipamientos colectivos, con un mayoritario protagonismo de la titularidad privada. Los recintos educativos, sanitarios y servicios de salud, y los usos terciarios, han intensificado la ocupación en este conjunto urbano. El proceso está lejos de paralizarse.

La revitalización funcional del barrio durante las últimas décadas puede representarse en la continuidad de centros educativos y sanitarios históricos que han mantenido su localización y su actividad pese a los crecientes requerimientos de la normativa sectorial. El Colegio Salesianos, el de Las Teresianas, los centros de educación a distancia del IBAD y la UNED, la Clínica de Santa Catalina (recientemente renovada), la Clínica de La Paloma, la Clínica del Carmen (ambas también rehabilitadas) conservan su plena vitalidad. No olvidemos que el ámbito localiza los hitos de dotaciones públicas del Ayuntamiento, la Comisaría de Las Palmas y varias instalaciones-residencias militares. El antiguo Estadio Insular se ha reconvertido en un Parque, añadiéndose a los parques Doramas y Romano como enclaves neurálgicos del ocio y el esparcimiento en la ciudad baja, así como las instalaciones deportivas vinculadas a la natación (Metropole, Julio Navarro). Pese a la transformación de la ciudad, todos los anteriores siguen siendo hitos significativos del sistema urbano de dotaciones y equipamientos colectivos.

Probablemente por unas condiciones paisajísticas y de calidad arquitectónica más favorecidas que en otras zonas de aparición más contemporánea, unido a las derivadas de su localización y accesibilidad, Ciudad Jardín experimenta signos de reconversión en un subcentro neurálgico dentro de la ciudad baja. Se ha convertido en un escenario específico y singular en la localización de inversiones, explicando que la ocupación superficial de los usos distintos al de vivienda sea superior.

Esas cualidades ambientales y de representatividad cultural está detrás de que el barrio sea el principal foco ajeno al Istmo (Playa de Las Canteras-Santa CatalinaLa Isleta) y al centro histórico (Vegueta-Triana) en la localización de viviendas vacacionales (nueva modalidad de alojamiento turístico de amplio desarrollo en el sistema urbano nacional). Y una cadena hotelera (Barceló) es responsable de la 
rehabilitación del emblemático Hotel Santa Catalina y el emplazamiento reciente de otro hotel en sus inmediaciones.

La localización de «franquicias» de la educación se ha convertido en un rasgo significativo de la imagen urbana del barrio, añadiéndose a los tradicionales (Hispano Inglés, Canterbury, Anita Conrad). Y similar efecto ha tenido la renovación de la histórica Clínica Santa Catalina (ahora Hospital VITHAS) que ha contaminado las manzanas de su entorno con un buen número de locales de servicios asociados (laboratorios, consultas, etc.) y el acompañamiento de otras empresas significativas en este campo (ICOT).

Como suele ocurrir en estos casos, el escaso atractivo en la localización de aparcamientos por su limitada rentabilidad ha derivado en la ocupación del espacio público viario para esta función. Ante la inexistencia de nuevos viarios, ésta desplaza en gran medida la oferta de los residentes (basada en las plazas en calle), quienes ven ampliada la dificultad impuesta por la normativa de protección del patrimonio arquitectónico para introducir garajes y la destacada demanda de espacio viario de tránsito y de estancia en estos nuevos usos.

No olvidemos que la calle León y Castillo (arteria fundamental del barrio) es un recorrido paralelo a la Autovía GC-1 (del sur) en el perímetro costero y se colinda con la intersección de ésta con la GC-2 (del norte), siendo una de las áreas más saturadas de la Isla. Las tensiones del proceso transformador en este paisaje cultural pueden ejemplificar uno de los principales conflictos que experimentan los barrios tradicionales y centros históricos del sistema urbano español.

La presión de las demandas particulares, los malabarismos en el equilibrio de la administración municipal en las autorizaciones, algunas sentencias judiciales contrarias a las tesis conservacionistas, entre otros factores, convierten la gestión pública del patrimonio cultural de este espacio urbano en un constante esfuerzo con variada casuística.

El resultado formal no es siempre el deseado para el interés general del paisaje. En determinados casos, la renovación se convierte en un estímulo en la conservación, rehabilitación y puesta en valor de ese conjunto, redundando en una impronta favorable en las cualidades del entorno. Estas incertidumbres no obvian la existencia de oportunidades en esa dinámica urbana que vemos dirigida directa o indirectamente hacia una puesta en valor de Ciudad Jardín como entidad cultural.

Ejemplos significativos del esfuerzo público y privado y esperanzadores para una sostenibilidad de este patrimonio urbano podemos representarlos en una intensificación del esfuerzo del Ayuntamiento mediante actuaciones que, con independencia de su efecto de mejora en piezas o enclaves locales, han sido consideradas intervenciones estratégicas en el contexto de la materialización del modelo de ciudad. Un impacto de interés en esta trascendencia ha sido la puesta en valor del ámbito en la escala municipal e insular y la focalización como espacio dotado de singularidad.

El proceso reciente se inició con la reconversión del antiguo Estadio Insular (perímetro exterior en el margen norte) en un parque arbolado de alta capacidad de población usuaria y de intercambio de cualidades paisajísticas con la entrada hacia el barrio de Las Alcaravaneras. Luego, la reurbanización culminada de la calle Pío XII ha derivado en una plataforma con mayoritaria presencia del espacio de tránsito peatonal, en bici, aprovechando la ejecución del tramo asociado a la implantación del recorrido de transporte público rápido (BRT, o aquí conocida 
como Metroguagua).

El último episodio por ahora ha sido la rehabilitación integral del conjunto de Hotel Santa Catalina, Parque Doramas y Pueblo Canario (aún en marcha en esta última pieza), cuyo efecto en la significación de este enclave emblemático de la ciudad ha venido acompañado de una mejora de sus cualidades ambientales. Es de esperar su influencia positiva en la valorización cultural y paisajística del barrio como referente del desarrollo sostenible y la consecución de un equilibrio viable con la modernización del dinamismo económico y funcional.

En definitiva, la conservación de un paisaje cultural urbano requiere que se mantenga el uso residencial y su vitalidad como organismo sostenible dentro de la ciudad, alejándolo de los riesgos de los núcleos históricos que se han convertido en museos al aire libre sin vida ajena al turismo. Este objetivo es una tensión en sí misma, por la necesidad de medidas revitalizadoras y una correcta coordinación entre los mecanismos legales de protección del patrimonio cultural, de ordenación urbanística como todo barrio y de gestión del espacio urbano. Las diferencias o discordancias de criterio y su aplicación en la trama y el conjunto arquitectónico por parte de estos frentes suelen ser fuentes de conflicto que amenazan la propia sostenibilidad del paisaje. Incluso, la propia dinámica que genera su atractivo produce una feroz competencia entre el uso residencial que da origen y define la condición urbana de estas zonas, por una parte, y la creciente implantación de servicios, de uso del espacio público y de actividades como el turismo, por otra.

\section{CONCLUSIONES}

La aplicación del Convenio Europeo del Paisaje y de la Agenda Urbana Española en Las Palmas de Gran Canaria tiene uno de sus escenarios singulares en el barrio de Ciudad Jardín, en tanto se demuestra su condición de paisaje urbano cultural.

A partir de una metodología de observación e interpretación de la estructura territorial y su manifestación de un conjunto de valores que distinguen la condición anterior, se constata la coexistencia en el ámbito de los rasgos de un origen y proceso de desarrollo histórico que se inicia en el tránsito del siglo XIX al XX, la diferenciación paisajística y morfológica respecto a los barrios que lo bordean, la conservación de un abundante patrimonio cultural y ambiental que distinguen cualitativamente el entorno y los riesgos de su atractivo y puesta en valor que se ejemplifican en la acogida de usos y una renovación funcional con diversos resultados de integración.

La conservación del tejido edificatorio, residencial y no residencial, de la trama de calles y espacios públicos, de los jardines y elementos naturales como protagonistas del entorno refleja, pese a la contaminación de los procesos contemporáneos, unas pautas culturales de ocupación y formalización del espacio que en su singularidad respecto al resto de la urbe forman parte imprescindible de su memoria geográfica.

Es un paisaje que globalmente no presenta la condición de bien de interés cultural con la categoría de "conjunto histórico», en tanto figura jurídica que se aplica en buena parte de los cascos históricos de la ciudad española (en Las Palmas de Gran Canaria se incluyen los casos colindantes de Vegueta, Triana y Perojo). 
Y, sin embargo, sus cualidades compositivas y paisajísticas son gestionadas por la administración pública mediante una ordenación urbanística volcada, pese a sus desaciertos locales, en su conservación como hito significativo e identitario de la imagen urbana y el desarrollo sostenible de la ciudad.

Hablamos de una entidad claramente identificada en la suma de casi dos centenares de inmuebles representativos de un proceso histórico promovido por la burguesía urbana del que resulta un muestrario de diseños propio de la arquitectura tradicional de reminiscencias europeas, de la arquitectura regionalista $\mathrm{y}$, sobre todo, de la arquitectura racionalista, conformando una biblioteca obligada para comprender capítulos básicos del patrimonio cultural del siglo xx en las islas.

Y ese bagaje constructivo se acompaña con el armazón natural de una red de jardines, parques públicos e impronta del arbolado en las calles, que observando el barrio desde el aire, manifiesta una destacada proporción de verde en el conjunto de su superficie. Lo relevante es que con mayor o menor herencia histórica, se integra con el conjunto arquitectónico hasta formar parte de su ADN. No se entiende este paisaje sin ambas características (arquitectura-trama urbana y elementos naturales) y sin esa conexión.

Los retos en la conservación de este paisaje se corresponden precisamente con su vocación y funcionalidad urbana. Su atractivo hace un efecto de llamada de nuevos usos y pautas constructivas o de actividad. Pueden ser necesarios para mantener la vitalidad del entorno y evitar la dilución de sus valores por degradación o marginalización en la identidad de la ciudad. Pero ¿dónde están los límites de la capacidad de acogida que permitan controlar un agravamiento de la contaminación ya evidenciada durante las últimas décadas?

Los mecanismos de la movilidad sostenible son imperativos en el futuro del espacio y en la solución al problema funcional de los aparcamientos y el sobredimensionamiento del tráfico interior. El recorrido del transporte público rápido y de la red de recorridos bici a lo largo de las vías principales abren el camino. Se discute la implantación de recorridos peatonales temáticos que se basan en la arquitectura y potenciar el atractivo turístico del ámbito, uniéndose al efecto de la rehabilitación integral del conjunto de Doramas, Hotel Santa Catalina y Pueblo Canario. Sin embargo, ¿Dónde están los límites de ese cambio de esquema de movilidad?, ¿Es conveniente la conversión de Ciudad Jardín en un museo al aire libre enfocado a la visita turística y el esparcimiento público? Es una zona residencial, y como tal competirá con esa función económica y recreativa.

Estas incertidumbres hacen más necesarios los mecanismos de la didáctica ciudadana, basada en las herramientas oficiales de la didáctica de las ciencias sociales, de la geografía, de la historia, del urbanismo. Herramientas formativas son tan imprescindibles como un esfuerzo más eficaz de la gestión urbana desde la Administración pública, poniendo al servicio de estas energías instrumentos estratégicos, jurídicos y de difusión del patrimonio cultural más versátiles, inteligentes e innovadores.

Es intención de quienes suscribimos este trabajo seguir ahondando en estas cuestiones. Pero, lo cierto es que estamos en Ciudad Jardín ante un paisaje urbano cultural con grandes posibilidades de sostenibilidad urbana, científicas y académicas. 


\section{REFERENCIAS}

Álvarez, A. et al. (2002): La Ciudad Jardín cien años después. Ciudades, 6, Instituto Universitario de Urbanística, Universidad de Valladolid, Valladolid.

Alemán, S. (2008): Las Palmas de Gran Canaria. Ciudad y Arquitectura (1870-1930), Cabildo de Gran Canaria, Las Palmas de Gran Canaria.

Arroyo, L. (1898). «Las Palmas de Gran Canaria», en Las Palmas de Gran Canaria a través de la Cartografía. 1588-1899. Cabildo de Gran Canaria, Casa de Colón y Museo Militar Regional de Canarias. Las Palmas de Gran Canaria: 168.

AlvargonzÁlez, R.(1999): Somió. La ciudad jardín de Gijón, Fundación Alvargonzález, Gijón.

BANDARín, F.; VAN OeRs, R. (2014): El paisaje urbano histórico, Abada Ed, Madrid.

Boyer, A. (1962): Plan General de Ordenación Urbana de Las Palmas de Gran Canaria, Ayuntamiento de Las Palmas de Gran Canaria, Las Palmas de Gran Canaria.

CÁceres, E. (1980): La formación urbana de Las Palmas, Escuela Técnica de Arquitectura de Las Palmas de Gran Canaria. Las Palmas de Gran Canaria.

CASARIEGO, J. (1986): «Las Palmas: 1922-1936», en El Cabildo y la Ciudad racionalista, Cabildo de Gran Canaria, Las Palmas de Gran Canaria: 83-87.

Castillo, J. (2009): "La dimensión territorial del patrimonio histórico», en Patrimonio histórico y desarrollo territorial, Universidad Internacional de Andalucía, Sevilla: 26-71.

Domínguez, J.; MoReno, C.; LóPez, R.; ConCePCión, J. (2009): Los torreones y miradores de Las Palmas de Gran Canaria, Editorial Anroart, Las Palmas de Gran Canaria.

De Terán, F. (1999): Historia del urbanismo en España (III). Siglos XIX y XX, Cátedra, Madrid.

GaGo, J.L. (2000): El desasosiego de la arquitectura neocanaria, Museo Néstor, Las Palmas de Gran Canaria.

GONZÁLEZ-VARAS, I. (1999): Conservación de bienes culturales. Teoría, historia, principios y normas, Cátedra, Madrid.

GuERRAND, R. (2002): «Sobre los orígenes del movimiento de las ciudades-jardines en Europa». Ciudades. La Ciudad Jardín Cien años después. $\mathrm{N}^{\circ}$ 6, Instituto Universitario de Urbanística, Universidad de Valladolid: 17-20.

Hernández, S. et al. (2014): Plan Especial de Protección de Vegueta-Triana, Ayuntamiento de Las Palmas de Gran Canaria, Las Palmas de Gran Canaria.

Hernández, S. et al. (2017): Plan Especial de Protección del Entorno de la Calle Perojo, Ayuntamiento de Las Palmas de Gran Canaria, Las Palmas de Gran Canaria.

HeRnÁNDEZ, S.; Ginés, M.C.; LozANO, M.Y. (2016): «Barrios tradicionales y espacio público. Usos y potencialidades en los Riscos de Las Palmas de Gran Canaria», en F. Morales (coord.), Actas del XxII Coloquio de Historia Canario-Americana, Cabildo Insular de Gran Canaria, Las Palmas de Gran Canaria: 1-11.

HerrerA, A., (1978): La ciudad de Las Palmas. Noticia histórica de su urbanización. Ayuntamiento de Las Palmas de Gran Canaria, Las Palmas de Gran Canaria.

LóPEZ, L., (1883): «Plano de la Ciudad de Las Palmas de Gran Canaria», en Las Palmas de Gran Canaria a través de la Cartografía. 1588-1899, Cabildo de Gran Canaria, Casa de Colón y Museo Militar Regional de Canarias. Las Palmas de Gran Canaria: 160-164.

LozAno, M.Y. (2013): La planificación de los conjuntos históricos en Gran Canaria, Tesis doctoral inédita, Universidad de Las Palmas de Gran Canaria, Las Palmas de Gran Canaria. 
Martín, F. (2001): Las Palmas. Ciudad y Puerto. Cinco siglos de evolución. Las Palmas de Gran Canaria, Fundación Puertos de Las Palmas, Las Palmas de Gran Canaria.

Mirallave, V. (2009): Zuazo y Las Palmas de Gran Canaria. 1940-1968, Cabildo de Gran Canaria, Las Palmas de Gran Canaria.

Morales, G, (1995): «La Ciudad Jardín de Las Palmas de Gran Canaria (18801994)», ERÍA. Revista Cuatrimestral de Geografía, 36: 89-99.

Navarro, F. (1911): «Plano de la Ciudad del Real de Las Palmas», en Las Palmas de Gran Canaria a través de la Cartografía. 1588-1899, Cabildo de Gran Canaria, Casa de Colón y Museo Militar Regional de Canarias, Las Palmas de Gran Canaria: $175-178$.

OJEDA, M.L. (2011): La arquitectura regionalista en la ciudad de Las Palmas de Gran Canaria. 1929-1955, Tesis doctoral inédita, Universidad de Las Palmas de Gran Canaria, Las Palmas de Gran Canaria.

RIVERA, J. (2010): «Paisaje y patrimonio», en Paisaje y Patrimonio, Abada Ed, Madrid: 11-30.

RodríGuez, L.; Peter, J., (2017): Bauhaus + Racionalismo. Miguel Martín + el Movimiento Moderno, Artshop Verlag, Berlín-Las Palmas de Gran Canaria.

Sobral, S. (1995): La formación suburbana de baja densidad del municipio de Las Palmas de Gran Canaria, CIES, Las Palmas de Gran Canaria.

Solana, E. et al. (2003): Crisis del barrio tradicional. Ruptura, mutación o continuidad, Universidad de Guadalajara y Universidad de Las Palmas de Gran Canaria, Guadalajara (México).

Tosco, C. (2009): «El paisaje histórico. Instrumentos y métodos de investigación», en Paisaje e historia, Abada Ed., Madrid: 89-110.

ZÁrAte, M. (2010): «Paisajes culturales urbanos. Un legado para conservar», Anales de Geografía, 30 (2): 187-210. 